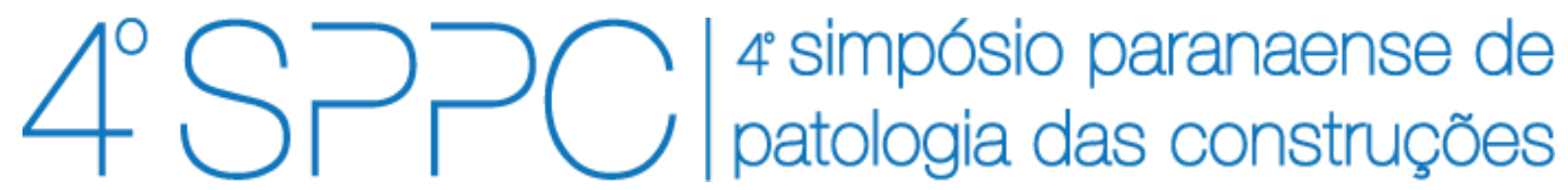

ISSN 2526-7248 artigo n. 4SPPC123, pp. 215-224, 2019

\title{
Ataque externo por ácido sulfúrico em pastas de cimento dosadas com silicato de sódio alcalino
}

Nenevê, Bruno Leandro 1; Dias, Roberto Luiz 2; Dobrovolski, Mateus E. G. ${ }^{3}$; Munhoz, Guilherme da S. 4; Godinho, Jayson Pereira ${ }^{5}$; Medeiros, Marcelo H. F. ${ }^{6}$

\author{
${ }^{1}$ Mestrando, Universidade Federal do Paraná, eng.neneve@gmail.com \\ 2 Mestrando, Universidade Federal do Paraná, robertoluizdias@hotmail.com \\ ${ }^{3}$ Mestrando, Universidade Federal do Paraná, munhoz.guilherme@outlook.com \\ ${ }^{4}$ Mestrando, Universidade Federal do Paraná, mateusdobrovolski@gmail.com \\ ${ }^{5}$ Doutorando, Universidade Federal do Paraná, jayson.godinho.eng@gmail.com \\ 6 Docente, Universidade Federal do Paraná, marcelo.ufpr@gmail.com
}

\begin{abstract}
Resumo: Dentre os ataques mais severos às matrizes cimentícias, destaca-se o decorrente do ácido sulfúrico $\left(\mathrm{H}_{2} \mathrm{SO}_{4}\right)$, que pode desenvolver-se em sistemas de coleta de esgoto. Para tanto, os agentes cristalizantes são capazes de trazer resultados positivos quanto à durabilidade através da redução da permeabilidade. Portanto, o presente artigo investigou a influência da adição de silicato de sódio alcalino em pastas de cimento exposta ao ataque por ácido sulfúrico. Fez-se uso de cimento CP V-ARI, cinza volante e superplastificante como demais materiais da mistura. Empregaram-se ensaios para avaliação de índice de vazios, absorção de água e FT-IR. Os resultados mostraram que o teor de adição de silicato de sódio alcalino e o ambiente de exposição influenciaram as características das amostras. As pastas com adição de silicato de sódio alcalino apresentaram menor degradação sob o ponto de vista dos ensaios de índice de vazios e absorção de água. O FT-IR evidenciou a formação dos produtos oriundos da degradação pelo ataque ácido.
\end{abstract}

Palavras-chave: Ataque ácido; Silicato de sódio alcalino; Pasta de cimento.

Abstract: Among the most severe attacks to the cementitious matrix, stands out the sulfuric acid $\left(\mathrm{H}_{2} \mathrm{SO}_{4}\right)$, which can develop in sewage collect systems. Therefore, the crystallizing agents are able to bring positive results regarding durability by reducing permeability. Thus, the present article investigated the influence of the alkali sodium silicate addition on cement pastes exposed to sulfuric acid attack. CP V-ARI cement, fly ash and superplasticizer were used as other materials of the mixture. Tests were used to evaluate the voids ratio, water absorption and FT-IR. The results showed that both the addition content of alkaline sodium silicate and the exposure environment influenced the characteristics of the samples. The pastes with alkali sodium silicate addition presented lower degradation from the point of view of the tests of voids index and water absorption. FT-IR evidenced the formation of the products from degradation by acid attack.

Keywords: Acid attack; Alkaline sodium silicate; Cement paste. 
NENEVÊ, B.L.; DIAS, R.L.; DOBROVOLSKI, M.E.G.; MUNHOZ, G.S.; GODINHO, J.P.; MEDEIROS, M.H.F. ATAQUE EXTERNO POR ÁCIDO SULFÚRICO EM PASTAS DE CIMENTO DOSADAS COM SILICATO DE SÓDIO ALCALINO. $4^{\circ}$ Simpósio Paranaense de Patologia das Construções (40 SPPC), artigo 4SPPC123, pp. 215 - 224, 2019. DOI: 10.4322/2526-7248.043

\section{Introdução}

Os sulfatos são considerados uns dos agentes químicos mais agressivos às matrizes cimentícias, podendo ser encontrados em diversas formas na natureza. A degradação do concreto devido ao ataque por sulfatos ocorre através de reações químicas desse íon $\left(\mathrm{SO}_{4}{ }^{2-}\right)$ com os compostos hidratados do cimento Portland e pode se manifestar de duas formas distintas: expansão associada à fissuração ou redução progressiva da resistência vinculada à perda de massa. No primeiro caso, após o início do processo de fissuração, os sulfatos tendem a penetrar com maior facilidade no interior do material, acelerando ainda mais o processo de deterioração. No segundo caso, ocorre a perda de coesão dos produtos de hidratação do cimento que resultam na desagregação da matriz cimentícia [1-2].

O ataque resultante para os diferentes tipos de solução de sulfato apresenta um diferente grau de severidade conforme sua origem, de modo que o ataque por ácido sulfúrico é considerado o mais severo, superando a degradação decorrente do sulfato de magnésio e do sulfato de sódio. $O$ ataque ácido pode apresentar-se de modo semelhante ao ataque tradicional por sulfatos, resultando em expansão e fissuração. Assim, o ataque às estruturas de concreto armado devido ao ácido sulfúrico pode ocorrer em ambientes com alta concentração de sulfeto de hidrogênio $\left(\mathrm{H}_{2} \mathrm{~S}\right)$, umidade e oxigênio atmosférico, configurando-se como uma das causas mais rápidas de degradação. Tal processo geralmente ocorre em sistemas de coleta de esgoto, reduzindo drasticamente a vida útil da infraestrutura e levando a perdas econômicas significativas [3-4].

As instalações convencionais de esgoto apresentam, no interior do elemento de concreto, duas zonas: o esgoto em si (contendo íons de sulfato e bactérias redutoras de sulfato) e a atmosfera resultante (que contém $\mathrm{H}_{2} \mathrm{~S}$, que é adsorvido pelas paredes de concreto). Assim, em decorrência da elevada umidade relativa, o sulfeto de hidrogênio gasoso dissocia-se em íons hidrogênio e íons sulfato. Por consequência, o ácido sulfúrico é produzido pelas reações de oxidação desses sulfatos, que por sua vez ataca as paredes cimentícias e produz gesso e etringita, que são expansivos e causam graves danos ao concreto em sistemas de esgoto [5-7].

Por outro lado, sabendo que a degradação das matrizes cimentícias está associada ao ingresso de agentes agressivos ao interior do concreto e, consequentemente, à permeabilidade, os agentes cristalizantes apresentam-se como um aditivo redutor de permeabilidade, capaz de trazer resultados positivos quanto à durabilidade. Tais agentes químicos, como o silicato de sódio, reagem com o hidróxido de cálcio, formando silicato de cálcio hidratado, que cresce no interior dos poros do concreto, reduzindo a permeabilidade e tornando-o mais estanque, sem que haja prejuízo à matriz [8-10]. Dessa forma, é possível mitigar os efeitos deletérios dos ataques externos aos compósitos cimentícios, evitando o ingresso dos agentes agressivos. Do mesmo modo, o silicato de sódio $\left(\mathrm{Na}_{2} \mathrm{SiO}_{3}\right)$ tem sido proposto como um potencial agente de autocicatrização em diferentes sistemas, apresentando resultados positivos quanto à recuperação de resistência mecânica e melhora na durabilidade [11-12].

Finalmente, o presente artigo tem por objetivo explicar a influência do silicato de sódio alcalino como agente cristalizante em pastas de cimento exposta ao ataque por sulfato resultante do ácido sulfúrico $\left(\mathrm{H}_{2} \mathrm{SO}_{4}\right)$, comum em instalações de esgoto. 
NENEVÊ, B.L.; DIAS, R.L.; DOBROVOLSKI, M.E.G.; MUNHOZ, G.S.; GODINHO, J.P.; MEDEIROS, M.H.F. ATAQUE EXTERNO POR ÁCIDO SULFÚRICO EM PASTAS DE CIMENTO DOSADAS COM SILICATO DE SÓDIO ALCALINO. $4^{\circ}$ Simpósio Paranaense de Patologia das Construções (40 SPPC), artigo 4SPPC123, pp. 215 - 224, 2019. DOI: 10.4322/2526-7248.043

\section{Materiais}

Para o desenvolvimento das pastas cimentícias, foram utilizados cimento CP V-ARI como aglomerante (equivalente ao cimento tipo III, conforme ASTM C150) e cinza volante classe $\mathrm{C}$ como adição mineral, com as características de ambas apresentadas na Tabela 1 e as composições químicas apresentadas na

Tabela 2. Ademais, apresenta-se o difratograma de cinza volante na Figura 1, pelo qual nota-se um tênue halo amorfo, característico de atividade pozolânica.

Tabela 1: Características físico químicas do cimento CP V-ARI e da cinza volante.

\begin{tabular}{cccc}
\hline \multirow{2}{*}{ Material } & \multicolumn{3}{c}{ Características } \\
\cline { 2 - 4 } & BET & Massa Específica & Atividade Pozolânica \\
\hline Cimento CP V-ARI & $1,070 \mathrm{~m}^{2} / \mathrm{g}$ & $3,13 \mathrm{~g} / \mathrm{cm}^{3}$ & - \\
Cinza volante & $1,096 \mathrm{~m}^{2} / \mathrm{g}$ & $1,95 \mathrm{~g} / \mathrm{cm}^{3}$ & $408 \mathrm{mg} \mathrm{Ca}(\mathrm{OH})_{2} / \mathrm{g}$ \\
\hline
\end{tabular}

Tabela 2: Composição química do cimento CP V-ARI e da cinza volante.

\begin{tabular}{|c|c|c|c|c|c|c|c|c|c|}
\hline \multirow[b]{2}{*}{ Aglomerante } & \multicolumn{9}{|c|}{ Composição química (\%) } \\
\hline & $\mathrm{CaO}$ & $\mathrm{SiO}_{2}$ & $\mathrm{Al}_{2} \mathrm{O}_{3}$ & $\mathrm{Fe}_{2} \mathrm{O}_{3}$ & MgO & $\mathrm{SO}_{3}$ & $\mathrm{~K}_{2} \mathrm{O}$ & $\begin{array}{l}\text { Demais } \\
\text { Óxidos }\end{array}$ & $\begin{array}{c}\text { Perda ao } \\
\text { Fogo }\end{array}$ \\
\hline Cimento CPV-ARI & 60,61 & 18,71 & 4,26 & 2,95 & 3,52 & 3,12 & - & - & 3,34 \\
\hline Cinza Volante & 1,60 & 57,80 & 26,30 & 6,20 & 0,80 & 0,30 & 3,00 & 1,78 & 1,99 \\
\hline
\end{tabular}

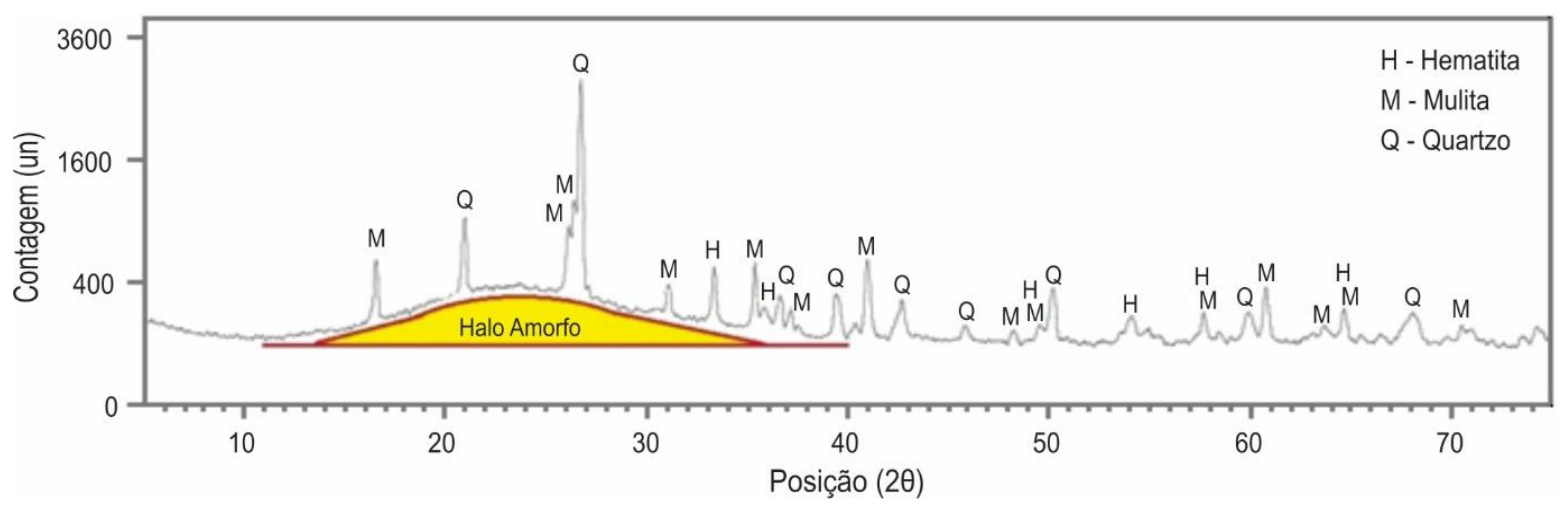

Figura 1: Difratograma de raios-X da cinza volante.

O Silicato de sódio alcalino, empregado como agente cristalizante, tem suas características apresentadas na Tabela 3.

Tabela 3: Características do agente cristalizante: silicato de sódio alcalino.

\begin{tabular}{ccccccc}
\hline $\begin{array}{c}\text { Densidade a } \\
\mathbf{2 5}{ }^{\circ} \mathbf{C}\left(\mathbf{g} / \mathbf{c m}^{3}\right)\end{array}$ & $\begin{array}{c}\text { Viscosidade } \\
(\mathbf{c P})\end{array}$ & $\begin{array}{c}\text { Oxido de } \\
\text { sódio (\%) }\end{array}$ & $\begin{array}{c}\text { Oxido de } \\
\text { silício (\%) }\end{array}$ & $\begin{array}{c}\text { Sólidos } \\
\text { totais (\%) }\end{array}$ & $\begin{array}{c}\text { Relação } \\
\left(\mathrm{SiO}_{2}\right) /\left(\mathrm{Na}_{2} \mathrm{O}\right)\end{array}$ & Água (\%) \\
\hline $1,560-1,585$ & $900-1400$ & $14,5-15,5$ & $30,5-34,0$ & $46,0-48,5$ & $1,96-2,34$ & $51,5-54,0$ \\
\hline
\end{tabular}


NENEVÊ, B.L.; DIAS, R.L.; DOBROVOLSKI, M.E.G.; MUNHOZ, G.S.; GODINHO, J.P.; MEDEIROS, M.H.F. ATAQUE EXTERNO POR ÁCIDO SULFÚRICO EM PASTAS DE CIMENTO DOSADAS COM SILICATO DE SÓDIO ALCALINO. $4^{\circ}$ Simpósio Paranaense de Patologia das Construções (40 SPPC), artigo 4SPPC123, pp. 215 - 224, 2019. DOI: 10.4322/2526-7248.043

\section{Métodos}

Este experimento foi todo desenvolvido em pasta, sendo focado nas modificações microestruturais ocasionadas pelo ataque por ácido sulfúrico. A pasta estudada é resultante de um concreto de traço 1: 1,90: 2,47, com uma relação água/ aglomerante de 0,45 - equivalente ao utilizado na construção de uma Estação de Tratamento de Esgoto (ETE) na cidade de Ponta Grossa/PR. Ademais, foi utilizado um aditivo superplastificante, à base de policarboxilato, com teor equivalente ao utilizado na mistura de concreto, necessário para obter a consistência especificada: abatimento fixado em $80 \pm 20 \mathrm{~mm}$. O silicato de sódio alcalino (SSA) foi empregado à mistura em três níveis de adição: 0 \% (referência), 1 \%, 5 \% e $10 \%$, resultando em 4 formulações distintas. O valor de $1 \%$ é mais recorrente em estudos [13-15], contudo, valores maiores também são empregados [16]. Deste modo, os teores de $5 \%$ e $10 \%$ foram arbitrados visando poder avaliar de maneira estatisticamente significativa a influência da adição aplicada, além de verificar o efeito resultante para maiores teores de adição do silicato de sódio alcalino. Na Tabela 4 são apresentados o consumo de material para cada formulação estudada.

Tabela 4: Consumo de material das formulações estudadas.

\begin{tabular}{cccccc}
\hline Teor de & \multicolumn{5}{c}{ Proporções de mistura $\left(\mathbf{k g} / \mathbf{m}^{\mathbf{3}}\right)$} \\
SSA & Cimento CP V-ARI & Cinza volante & Água & Aditivo SP & SSA \\
\hline $0 \%$ & 770,89 & 415,10 & 533,70 & 4,74 & 0,00 \\
$1 \%$ & 765,11 & 411,98 & 523,81 & 4,71 & 11,77 \\
$5 \%$ & 737,92 & 397,34 & 482,48 & 12,49 & 56,76 \\
$10 \%$ & 694,42 & 373,92 & 427,33 & 41,67 & 106,83 \\
\hline
\end{tabular}

Para a realização do programa experimental, forma moldados corpos de prova cilíndricos (22 mm de diâmetro por $44 \mathrm{~mm}$ de altura), os quais foram submetidas aos ensaios de absorção de água, índice de vazios e caracterização microestrutural por meio de FT-IR. As amostras de pasta foram desmoldadas 48 horas após a moldagem e submetidas à cura submersa em água saturada com cal por um período de 26 dias, totalizando 28 dias de idade, a contar da data de moldagem. Em seguida, as amostras foram divididas em dois grupos: um grupo foi exposto à submersão em uma solução de ácido sulfúrico (AS) com pH entre 2,0 e 3,5, controlada periodicamente de modo a manter constante a agressividade do ataque ácido [17-18]; e o outro grupo de amostras permaneceu em solução de água saturada com cal (AC), sem que houvesse exposição ao ataque ácido. Na Tabela 5 são elencados os tratamentos utilizados e suas respectivas codificações. Ademais, os corpos de prova foram ensaiados nas idades de 0,14, 56 dias de exposição, a contar a partir do período submerso em água saturada com cal (28 dias).

Tabela 5: Código de identificação das formulações estudadas.

\begin{tabular}{ccccc|cccc}
\hline Tratamento & AS-00 & AS-01 & AS-05 & AS-10 & AC-00 & AC-01 & AC-05 & AC-10 \\
\hline Ambiente de exposição & \multicolumn{3}{c}{ Solução de ácido sulfúrico } & \multicolumn{5}{c}{ Água saturada com cal } \\
Teor de SSA & $0 \%$ & $1 \%$ & $5 \%$ & $10 \%$ & $0 \%$ & $1 \%$ & $5 \%$ & $10 \%$ \\
\hline
\end{tabular}


O ensaio de determinação do índice de vazios e absorção por imersão seguiram o procedimento indicado pela norma ASTM C642-97 [19]. As amostras caracterizadas por meio da Espectroscopia de Infravermelho por Transformada de Fourier (FT-IR) foram finamente moídas em um moinho de panelas, sendo analisado apenas o material passante na peneira de 325 mesh $(0,044 \mathrm{~mm})$. Foram ensaiadas somente as amostras de idade 0 dias e 56 dias de exposição ao ácido sulfúrico, por conta da limitação de uso do equipamento, sendo que essas idades foram escolhidas por serem os dois extremos de exposição, possibilitando uma avaliação microestrutural que contemplou uma maior variação na formação e/ou degradação de compostos da pasta cimentícia. Para o ensaio foi utilizado um espectrofotômetro da marca Varian, modelo 640-IR com anexo de ATR (Attenuated total reflection - reflectância total atenuada) da marca Pike, modelo Miracle com cristal de ZnSe. Finalmente, para validação estatística dos resultados, foram empregados a análise de variância ANOVA e o teste Tukey, a fim de verificar a significância dos diversos resultados.

\section{Resultados e discussões}

Estão contidos na Tabela 6 os resultados de índice de vazios das pastas de cimento. Por outro lado, na Figura 2 estão representadas as variações do índice de vazios relativo das pastas de cimento. Dessa forma, no gráfico é expresso a diferença do índice de vazios entre ambas condições de exposição em uma mesma idade. Observase no gráfico que, para a idade de 14 dias, houveram dois resultados negativos. Isso significa que nesses casos o valor do índice de vazios para as amostras AC (água com cal) foi superior ao das amostras AS (ácido sulfúrico). Tal fato pode ser explicado pelas reações expansivas que ocorrem na situação do ataque ácido, colmatando os poros e reduzindo, assim, o índice de vazios.

Tabela 6: Índice de vazios das pastas de cimento.

\begin{tabular}{|c|c|c|c|c|c|c|c|c|}
\hline \multirow[b]{3}{*}{ Dias } & \multicolumn{8}{|c|}{ Percentual (\%) } \\
\hline & \multicolumn{4}{|c|}{ Água saturada com cal } & \multicolumn{4}{|c|}{ Solução com ácido } \\
\hline & AC-00 & AC-01 & AC-05 & AC-10 & AS-00 & AS-01 & AS-05 & AS-10 \\
\hline 0 & 42,28 & 43,23 & 44,29 & 48,19 & 42,28 & 43,23 & 44,29 & 48,19 \\
\hline 14 & 43,22 & 43,93 & 43,04 & 46,03 & 44,21 & 45,71 & 41,13 & 42,75 \\
\hline 56 & 36,30 & 45,15 & 42,49 & 44,31 & 43,44 & 51,67 & 47,31 & 47,61 \\
\hline
\end{tabular}

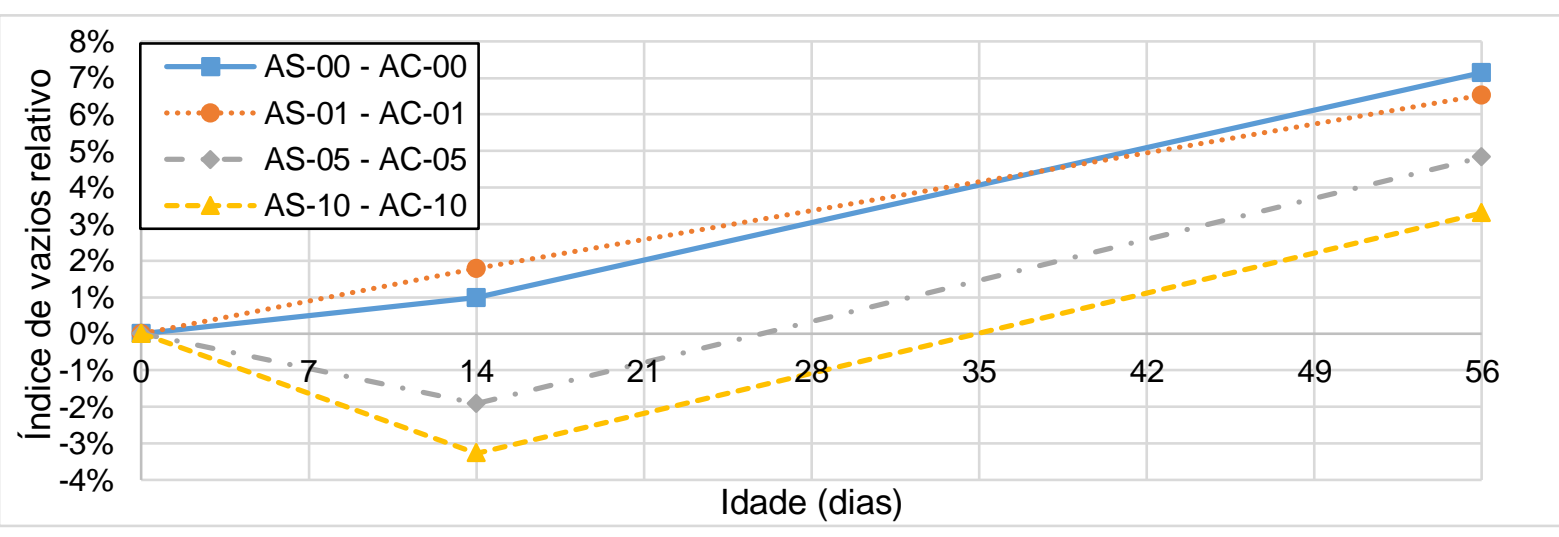

Figura 2: Índice de vazios relativo das pastas de cimento (resultado de exposição ao ácido sulfúrico subtraído do resultado na água com cal). 
Contudo, para a idade de 56 dias todos os resultados possuem valor positivo, significando que o índice de vazios relativo das pastas submetidas ao ataque ácido foi superior ao das amostras submetidas à água com cal. Tal explicação decorre de outro mecanismo de manifestação do ataque ácido, de modo que a formação de produtos como gipsita e etringita permitiu a formação de uma maior quantidade de vazios ao longo do tempo, por causa da deterioração da matriz atacada. Ademais, nota-se ainda que, para a idade de 56 dias, quanto maior o teor de adição de silicato de sódio alcalino, menor foi a variação do índice de vazios entre as duas condições de exposição, com a ressalva de que 0 \% e 1 \% não possuem variação estatística significativa, tanto para 14 quanto para 56 dias de idade de ensaio.

Estão apresentados na Tabela 7 os resultados de absorção de água das pastas de cimento de modo discriminado. Os resultados de absorção de água relativa estão ilustrados na Figura 3, sendo estes valores equivalentes à diferença entre os resultados da condição AS e AC para cada idade.

Tabela 7: Absorção de água das pastas de cimento.

\begin{tabular}{ccccc|cccc}
\hline & \multicolumn{8}{c}{ Percentual (\%) } \\
\cline { 2 - 9 } & \multicolumn{1}{c}{ Água saturada com cal } & \multicolumn{4}{c}{ Solução com ácido } \\
\hline Dias & AC-00 & AC-01 & AC-05 & AC-10 & AS-00 & AS-01 & AS-05 & AS-10 \\
\hline 0 & 31,32 & 32,40 & 32,40 & 37,81 & 31,32 & 32,40 & 32,40 & 37,81 \\
14 & 32,01 & 31,24 & 32,28 & 37,73 & 32,60 & 33,82 & 34,20 & 38,56 \\
56 & 26,51 & 32,09 & 31,36 & 35,61 & 35,21 & 37,05 & 37,17 & 39,60 \\
\hline
\end{tabular}

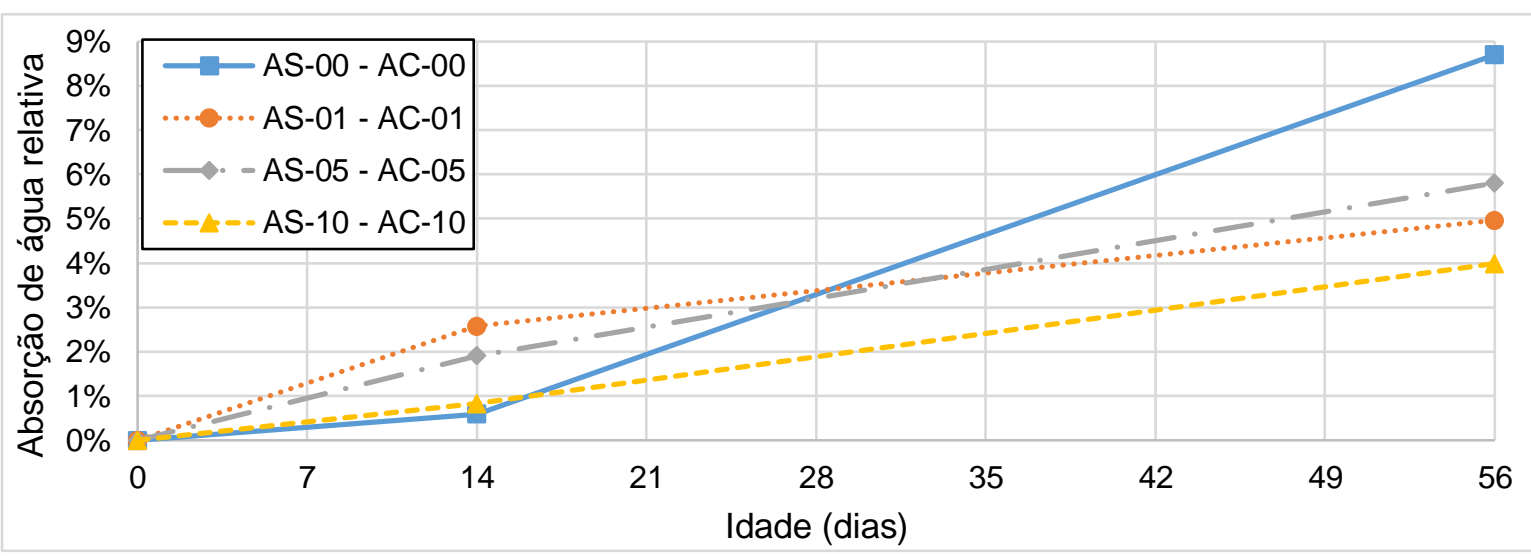

Figura 3: Absorção de água relativa das pastas de cimento (resultado de exposição ao ácido sulfúrico subtraído do resultado na água com cal).

Nota-se certa similaridade entre o que foi observado para a caracterização por índice de vazios, tal como esperado. Além disso, os resultados foram crescentes ao longo do tempo, denotanto o efeito gradual do ataque ácido. Ademais, tal como no ensaio de índice de vazios, a formulação de referência foi a que resultou em maior variação entre as duas condições de exposição, permitindo inferir que o ataque foi mais significativo, sob o ponto de vista de absorção de água nessa formulação que nas demais. Desta maneira, aos 56 dias de ensaio observa-se que a adição de silicato de sódio alcalino permitiu uma menor variação de absorção de água, comparando a exposição ao ácido e à água saturada com cal - resultando, portanto, em efeito positivo sob este aspecto.

Prosseguindo, apresentam-se na Figura 4 os resultados da análise de espectroscopia de infravermelho por transformada de fourier (FT-IR) para as pastas nas idades 0 e 56 
NENEVÊ, B.L.; DIAS, R.L.; DOBROVOLSKI, M.E.G.; MUNHOZ, G.S.; GODINHO, J.P.; MEDEIROS, M.H.F. ATAQUE EXTERNO POR ÁCIDO SULFÚRICO EM PASTAS DE CIMENTO DOSADAS COM SILICATO DE SÓDIO ALCALINO. $4^{\circ}$ Simpósio Paranaense de Patologia das Construções (40 SPPC), artigo 4SPPC123, pp. 215 - 224, 2019. DOI: 10.4322/2526-7248.043

dias após a cura, contendo $0 \%, 1 \%, 5 \%$ e $10 \%$ de SSA, expostas à solução de ácido sulfúrico.

É possível verificar pela transmitância que a formação dos produtos da reação com o $\mathrm{H}_{2} \mathrm{SO}_{4}$ (etringita secundária e gipsita) aumentou ao longo do tempo, em especial nas pastas contendo $1 \%, 5 \%$ e $10 \%$ de $\mathrm{Na}_{2} \mathrm{SiO}_{3}$ (itens $\mathrm{B}, \mathrm{C}$ e D da Figura 4), ressalvando que este é um ensaio qualitativo. Desse modo, fica evidente a ocorrência da formação dos produtos resultantes do ataque ácido, tal como esperado. Assim, demonstra-se que, de fato, houve ataque às matrizes das pastas de cimento, influenciando nos resultados anteriores de índice de vazios e absorção de água.

Ademais, a redução no pico da transmitância da portlandita em conjunto com o aumento do pico do silicato de cálcio hidratado (C-S-H) ao longo do tempo evidencia a ocorrência tanto da reação pozolânica como da progressão da hidratação do cimento, além do ataque ácido em si [20-23].

Indo mais adiante, comparando as diferentes amostras entre si, nota-se que a formulação AS-00 foi a que apresentou picos menos acentuados de transmitância, indicando que possivelmente o ataque foi menos significativo neste caso. Não obstante, as amostras com adição de SSA (AS-01, AS-05 e AS-10) obtiveram picos mais acentuados, indicando qualitativamente uma formação mais intensa de produtos do ataque ácido (gipsita e etringita).

Dessa forma, infere-se que, quanto à formação dos produtos resultantes do ataque ácido (gipsita e etringita), as pastas de cimento contendo adição de SSA foram mais sensíveis ao ataque por $\mathrm{H}_{2} \mathrm{SO}_{4}$, embora os resultados de índice de vazios e absorção de água tenham apresentado menor variação em decorrência do ataque para estas amostras.

É possível que o fato de as séries com silicato de sódio alcalino (SSA) terem sido menos afetadas em termos de aumento do índice de vazios e absorção pelo ataque ácido pode ser explicado pelo efeito de preenchimento dos poros pelos produtos de reação, etringita e gipsita.

\section{Conclusões}

Avaliando o emprego do $\mathrm{Na}_{2} \mathrm{SiO}_{3}$ alcalino na mitigação do ataque por $\mathrm{H}_{2} \mathrm{SO}_{4}$ em estações de tratamento de esgoto, infere-se que:

- Houve consumo da portlandita em virtude de: reação pozolânica (presença de cinza volante); recombinação química do $\mathrm{Na}_{2} \mathrm{SiO}_{3}$ (formação de $\mathrm{C}-\mathrm{S}-\mathrm{H}$ ); ataque por $\mathrm{H}_{2} \mathrm{SO}_{4}$ (formação de etringita secundária e gipsita);

- As pastas com adição de silicato de sódio alcalino apresentaram menor variação na comparação do índice de vazios e absorção de água, comparando a exposição na água com cal e na solução com ácido sulfúrico.

- Pelos ensaios de FT-IR, evidenciou-se a degradação por ataque ácido e confirmou-se a formação de produtos como etringita e gipsita, oriundos da reação deletéria com o $\mathrm{H}_{2} \mathrm{SO}_{4}$, sustentando as demais conclusões.

- A menor redução no índice de vazios e absorção encontrada nas séries com silicato de sódio alcalino pode ter sido causada pelo acúmulo do material de degradação na rede de poros do concreto. 

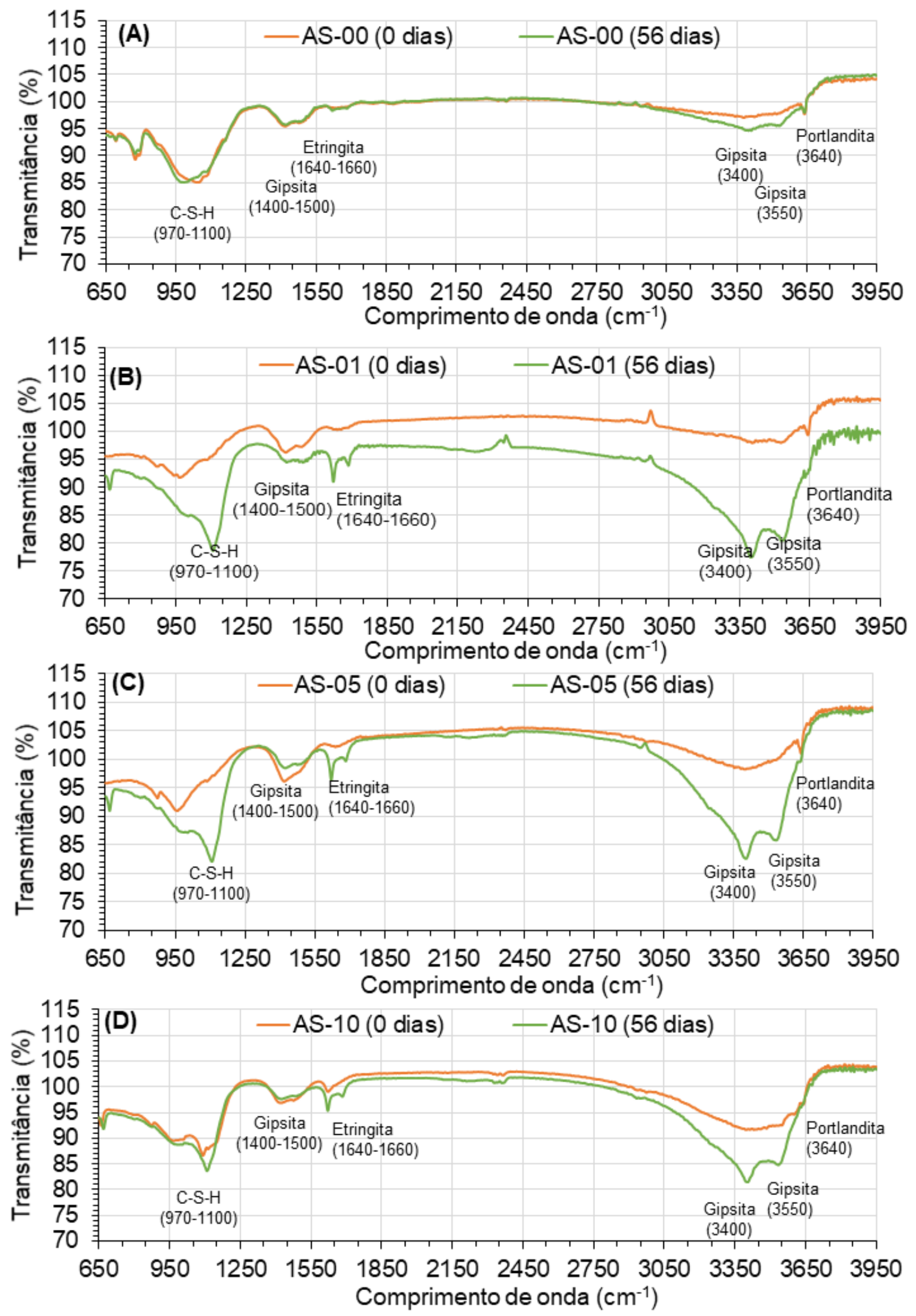

Figura 4: Análise de FT-IR ao longo do tempo de pastas de cimento contendo (A) 0 $\%$, (B) $1 \%$, (C) $5 \%$ e (D) $10 \%$ de $\mathrm{Na}_{2} \mathrm{SiO}_{3}$ expostos ao $\mathrm{H}_{2} \mathrm{SO}_{4}$. 
NENEVÊ, B.L.; DIAS, R.L.; DOBROVOLSKI, M.E.G.; MUNHOZ, G.S.; GODINHO, J.P.; MEDEIROS, M.H.F. ATAQUE EXTERNO POR ÁCIDO SULFÚRICO EM PASTAS DE CIMENTO DOSADAS COM SILICATO DE SÓDIO ALCALINO. $4^{\circ}$ Simpósio Paranaense de Patologia das Construções (40 SPPC), artigo 4SPPC123, pp. 215 - 224, 2019. DOI: 10.4322/2526-7248.043

\section{Agradecimentos}

Os autores expressam a sua gratidão à Universidade Federal do Paraná (UFPR), especificamente ao Departamento de Construção Civil (DCC), ao Programa de PósGraduação em Engenharia de Construção Civil (PPGECC), ao Centro de Estudos de Engenharia Civil (CESEC), ao Laboratório de Materiais e Estruturas (LAME), ao Centro de Microscopia Eletrônica (CME), ao grupo de pesquisa de Patologia e Recuperação das Construções (PRC), ao Laboratório Multiusuário de Análises Químicas (LAMAQ) da Universidade Tecnológica Federal do Paraná - UTFPR e, também, às empresas Cia. de Cimentos Itambé, Buschle \& Lepper S.A, MCBauchemie Brasil e a Lubeco Ind. e Com. de Lubrificantes Vegetais Ltda, pela doação de material para a pesquisa.

\section{Referências}

[1] Mehta, P. K.; Monteiro, P. J. M. Concreto: Estrutura, propriedades e materiais. São Paulo. Pini. 2014.

[2] Zhou, C.; Zhu, Z.; Wang, Z.; Qiu, H. Deterioration of concrete fracture toughness and elastic modulus under simulated acid-sulfate environment. Construction and Building Materials, Volume 176, 2018. Pages 490-499, ISSN 0950-0618.

[3] Monteny, J.; Vincke, E.; BEeldens, A.; de Belie, N.; Taerwe, L.; Van Gemert, D.; Verstraete, D. Chemical, microbiological, and in situ test methods for biogenic sulfuric acid corrosion of concrete. Cement and Concrete Research. 2000.

[4] Grandclerc, A.; Dangla, P.; Gueguen-Minerbe, M.; Chaussadent, T. Modelling of the sulfuric acid attack on different types of cementitious materials. Cement and Concrete Research. Volume 105, 2018. Pages 126-133. ISSN 0008-8846.

[5] Okabe, S.; Odagiri, M.; Ito, T.; Satoh, H. Succession of sulfur-oxidizing bacteria in the microbial community on corroding concrete in sewer systems. Appl. Environ. Microbiol. 2007. 971-980.

[6] Alexander, M.G.; Fourie, C. Performance of sewer pipe concrete mixtures with Portland and calcium aluminate cements subject to mineral and biogenic acid attack. Mater. Struct. 44. 2010. 313-330.

[7] Girardi, F.; Vaona, W.; DI Maggio, R. Resistance of different types of concretes to cyclic sulfuric acid and sodium sulfate attack, Cement and Concrete Composites, Volume 32, Issue 8, 2010, Pages 595-602, ISSN 0958-9465.

[8] Thompson, J. L.; Silsbee, M. R.; Gill, P. M.; Scheetz, B. E. Characterization of silicate sealers on concrete. Cement and Concrete Research, v. 27, n. 10, p. 15611567, 1997.

[9] Medeiros, M. H. F.; Pereira, E.; Helene, P. Tratamento de superfície com silicato de sódio para concreto: penetração de cloretos e absorção de água. Revista ALCONPAT, [S.I.], v. 2, n. 3, p. 149 - 160, sep. 2012.

[10] Zhang, Q.; Hu, X.-M.; Wu, M.-Y.; Zhao, Y.-Y.; Yu, C. Effects of different catalysts on the structure and properties of polyurethane/water glass grouting materials. J. Appl. Polym. Sci. 135. 2018. 46460. 
[11] Alghamri, R.; Kanellopoulos, A.; Al-Tabbaa, A. Impregnation and encapsulation of lightweight aggregates for self-healing concrete. Construction and Building Materials, Volume 124. 2016. Pages 910-921, ISSN 0950-0618.

[12] Gu, L.; Visintin, P.; Bennett, T. Evaluation of accelerated degradation test methods for cementitious composites subject to sulfuric acid attack; application to conventional and alkali-activated concretes. Cement and Concrete Composites. Volume 87. 2018. Pages 187-204. ISSN 0958-9465.

[13] Gomes, N. S. Influência de ativadores químicos na penetração de cloretos em concretos de mistura binárias e tenárias. Dissertação de Mestrado. UFSM. 2013.

[14] Kazemian, S.; Huat, B. B. K.; Mohammed, T. A.; Barghchi, M. The effect of sodium silicate on cement-sodium silicate system grout. Modern Methods and Advances in Structural Engineering and Construction. 1. Ed. Singapore: Chennai, p.659-663, 2011. DOI: 10.3850/978-981-08-7920-4S2-G01-cd

[15] Lone, I. H.; Muneeb, A.; Ahmad, J.; Jasim, S. M.; Ali, M.; Khan, M. A.; Malik, A. $\mathrm{H}$. Experimental study of effect of Sodium silicate (Na2SiO3) on properties of concrete. International Journal of Civil Engineering and Technology. Tamilnadu, v.6, p. 39-47, 2015.

[16] Raisdorfer, J.W., et al. Caracterização de concretos tratados com produtos cristalizantes para impermeabilização de piscinas com tratamento de água a base de cloreto de sódio. Revista de Engenharia e Tecnologia. 2013.

[17] De Belie, N.; Monteny, J.; Taerwe, L. Apparatus for accelerated degradation testing of concrete specimens, Mater. Struct. 35 (7) (2002) 427-433.

[18] De Belie, N.; Monteny, J.; Beeldens, A.; Vincke, E.; Van Gemert, D.; Verstraete, W. Experimental research and prediction of the effect of chemical and biogenic sulfuric acid on different types of commercially produced concrete sewer pipes, Cement Concr. Res. 34 (12) (2004) 2223-2236.

[19] ASTM C642-97, Standard Test Method for Density, Absorption, and Voids in Hardened Concrete. ASTM International, West Conshohocken, PA, 1997.

[20] Knapen, E; Van-Gemert, D; Cement hydration and microstructure formation in the presence of water-soluble polymers, Cement and Concrete Research, v. 39, no. 1, p. 6-13, 2009.

[21] Panzera, T. H; Sabariz, A. L. R; Borges, P. H. R; Vasconcelos, D. C. L; WASCONCELOS, W. L; Propriedades mecânicas de materiais compósitos à base de cimento Portland e resina epóxi. Cerâmica. v. 56, p. 77-82, 2010.

[22] Lafuente B; Downs R. T; Yang H; Stone N; The power of databases: the RRUFF project. In: Highlights in Mineralogical Crystallography, ARMBRUSTER, T; DANISI, R. M; eds. Berlin, Germany, W. De Gruyter, p. 1-30, 2015.

[23] Piqué, T. M; Vázquez; Uso de Espectroscopía Infrarroja con Transformada de Fourier (FT-IR) en el Estudio de la Hidratación del Cemento; Concreto Y Cemento. Investigación Y Desarrollo; Colônia Florida, México, v. 3, p. 62-71, 2012. 